Carvalho-Junior, O.O.; Sperb, R.M. A bacia catarinense do Rio Uruguai e o turismo de conservação como ferramenta ao desenvolvimento sustentável regional. Revista Brasileira de Ecoturismo, São Paulo, v.5, n.1, jan/abr-2012, pp.67-86.

\title{
A bacia catarinense do Rio Uruguai e o turismo de conservação como ferramenta ao desenvolvimento sustentável regional
}

\author{
The basin of Uruguay River in Santa Catarina (Brazil) and the conservation \\ tourism as a tool for sustainable regional development
} Oldemar de Oliveira Carvalho Junior, Rafael Medeiros Sperb

\begin{abstract}
RESUMO
O conceito de turismo de conservação ainda não é bem definido, sendo pouco conhecido no Brasil. A preocupação com a definição do conceito procede a partir do momento que o turismo de conservação pode representar uma alternativa econômica importante na gestão de projetos de biodiversidade em Unidades de Conservação, em especial Áreas de Proteção Ambiental (APA). Este tipo de turismo estimula a participação de diferentes setores da sociedade, facilitando a resolução de situações conflitivas, além de contribuir para modificar realidades adversas e melhorar a qualidade de vida das comunidades. O Rio Uruguai constitui um exemplo de interesses conflitivos, dentre os quais, projetos de usinas hidrelétricas para geração de energia têm levado vantagem frente a outras iniciativas. Modificações da paisagem natural resultam em provocações sociais que acabam por afetar o sistema econômico regional. O presente trabalho tem como característica produzir um banco de dados organizado e produtos como mapas temáticos de forma a subsidiar ações voltadas ao desenvolvimento sustentável regional. Para tanto, expedições ao campo e análises de imagens orbitais do satélite LANDSAT ETM7+, nas bandas do infravermelho 4 e 7, e bandas do visível 3, 2 e 1, foram realizadas. O Banco de Dados em SIG incluiu Associações de Municípios, Colonização, Cultura, Densidade Populacional, IDH (Índice de Desenvolvimento Humano), PIB (Produto Interno Bruto), Turismo de Aventura, Festas, Lazer, Hospedagem, Instituições de Ensino, Enem (Exame Nacional do Ensino Médio), Produção Agrícola (Erva-Mate, Maçã, Pinhão, Nó-de-Pinho, Uva), Ferrovias, Veículos, Hospitais, Número de Habitantes e Unidades de Conservação. A porção catarinense abordada nesse trabalho abrange 8 Bacias Hidrográficas: Peperi-Guaçu, Antas, Chapecó, Irani, Jacutinga, Peixe, Canoas e Pelotas. O trabalho é desenvolvido para o período de um ano, de Agosto de 2009 a Agosto de 2010. Um total de 210 mapas temáticos foram produzidos em diferentes escalas. Os resultados revelam áreas com baixos níveis de intervenção urbana ao longo das margens do Rio Uruguai. Os dados de IDH (média de 0,78 ) dão uma amostra do potencial que a Bacia do Rio Uruguai possui para o desenvolvimento de um turismo sustentável, responsável e/ou de conservação. Educação, por exemplo, é um fator primordial para o estabelecimento de práticas sustentáveis. Um aspecto importante a ser considerado nesse projeto é o status de conservação dos ecossistemas. Dentro da Bacia Hidrográfica do Rio Uruguai existem apenas 21 Unidades de Conservação de diferentes categorias, 2 RPPNs, 10 Unidades de Conservação Municipais, 3 Unidades de Conservação Estaduais e 6 Unidades de Conservação Federais. A soma das áreas dessas UCs totaliza cerca de $585 \mathrm{~km}^{2}$, o que representa algo em torno de $1.17 \%$ da área da Bacia $\left(50.200 \mathrm{~km}^{2}\right)$. A utilização do SIG, como instrumento de gestão se mostrou bastante útil devido à possibilidade de gerenciamento de grande volume de dados, análise do mundo real e simulações de situações diversas. Soma-se a isso o fato de que novos dados podem ser incorporados ao sistema a qualquer momento, tornando mais segura qualquer tomada de decisão ou solução de uso conflitivo.
\end{abstract}

PALAVRAS-CHAVE: Ecoturismo; Conservação; Turismo Sustentável. 
A bacia catarinense do Rio Uruguai e o turismo de conservação como ferramenta ao desenvolvimento sustentável regional

\section{ABSTRACT}

The concept of conservation tourism is not well defined, being little known in Brazil. The concern with the definition of conservation tourism can be justified from the possibility that it may represent an economical alternative in the management of biodiversity projects in protected areas, particularly the Environmental Protection Area (APA). This type of tourism encourages the participation of different sectors of society, facilitating the resolution of conflict situations, contributing to modify adverse realities and improving the quality of life of communities. The Uruguay is an example of conflicting interests, among which hydropower projects for power generation have taken advantage compared to other initiatives. Modifications of the natural landscape result in social provocations that ultimately affect the regional economic system. This work is characterized by producing an organized database and products such as thematic maps in order to support actions aimed at sustainable regional development. To this end, the field expeditions and analysis of orbital images from LANDSAT ETM7+, in the infrared bands 4 and 7 and in the visible bands 3, 2 and 1, were performed. The GIS database included Associations of Municipalities, Colonization, Culture, Population Density, IDH (Human Development Index), PIB (Gross Domestic Product), Adventure Tourism, Events, Entertainment, Lodging, Educational Institutions, Enem (National Survey of Secondary Education), Agricultural Production (Yerba Mate, Apple, Araucaria Pine Nuts, PineKnot, Grape), Railroads, Vehicles, Hospitals, Number of Inhabitants and Conservation Areas. The portion of Santa Catarina addressed in this work covers 8 watershed: Peperi Guaçu, Antas, Chapecó, Irani, Jacutinga, Peixe, Pelotas and Canoas. The work is developed for a period of one year, from August 2009 to August 2010. A total of 210 thematic maps were produced at different scales. The results reveal areas with low levels of urban intervention along the banks of the River Uruguay. The IDH data (average 0.78) gives a sample of the potential of the Uruguay River Basin has for the development of sustainable, responsible and/ or conservation tourism. Education, for example, is a key factor for the establishment of sustainable practices. An important aspect to be considered in this project is the conservation status of ecosystems. Within the Uruguay River Basin there are only 21 protected areas in different categories, 2 private reserves, 10 protected municipal areas, 3 state conservation areas and 6 federal conservation areas. The sum of these conservation areas totals about $585 \mathrm{~km}^{2}$, which represents around $1.17 \%$ of the study area $\left(50.200 \mathrm{~km}^{2}\right)$. The use of GIS as a management tool has proved useful to manage and analysis of large volumes of data, as well as real-world simulations of different situations. Important to pint out that new data can be incorporated into the system at any time, facilitating any decision related to conflicting uses.

KEYWORDS: Ecotourism; Conservation; Sustainable Tourism.

\section{Introdução}

O turismo de conservação implica na participação ativa do turista em ações voltadas para a conservação da biodiversidade. Dentro de um projeto de pesquisa, o turismo de conservação pode ser visto como um tema transversal, podendo, inclusive, representar uma ferramenta de mobilização social. No mês de Setembro de 2010, em diferentes datas, buscas no site Google Brasil com a expressão turismo de conserva- 
ção, resultaram em 0 (zero) de retorno, tanto para páginas como para títulos da internet. A maior parte dos resultados associaram o turismo em Unidades de Conservação, mas não exatamente o turismo de conservação.

A preocupação com a definição do conceito procede a partir do momento que o turismo de conservação pode representar uma alternativa econômica importante em Unidades de Conservação, em especial Áreas de Proteção Ambiental (APAs) (HOEFFEL et al., 2008). Contudo, o enfoque meramente econômico trás consigo o risco de que o discurso do turismo de conservação caia no mesmo sentido reducionista do "sustentável". O potencial do turismo como estimulador de rede social, aproximando diferentes culturas e povos, não deve ser negligenciado, principalmente se pode ser aplicado para modificar realidades adversas ou impeditivas à melhoria de qualidade de vida.

A banalização do termo "turismo sustentável" vem do fato de que as propostas podem se encaixar dentro de uma escala que vai do zero ao infinito, fruto de diferentes interesses, visões e experiências a respeito do uso dos recursos naturais (LEFF, 2002). Numa tentativa de estreitar a discussão sobre o tema, pode-se lançar mão de outros conceitos como "turismo de base comunitária" e "biodiversidade". Portanto, turismo de conservação de base comunitária e/ou para a conservação da biodiversidade, é outro termo que pode ser aplicado de forma a melhor contextualizar, tanto na mídia como no meio acadêmico, o que de fato vem a ser o turismo de conservação.

Independentemente de qualquer discussão ou polêmica referente à definição de turismo de conservação, qualquer atividade que almeja ser enquadrada como tal deve atender a requisitos mínimos que a caracterizem. Ou seja, deve estar associado a um projeto de conservação, envolver a comunidade como personagem principal, e aplicar técnicas de educação ambiental voltadas a mobilização social. O principal objetivo do turismo de conservação deve ser estimular a participação de uma gama maior das diferentes partes, facilitando a resolução de situações conflitivas, modificando realidades adversas e melhorando a qualidade de vida.

O Rio Uruguai, em particular, constitui um exemplo de interesses conflitivos, dentre os quais, projetos de usinas hidrelétricas para geração de energia têm claramente levado vantagem. Um perfil do Rio Uruguai, em sua totalidade, com as principais hidrelétricas pode ser vista na Figura 1. Problemas ambientais, culturais, econômicos e sociais têm se agravado desde então, resultado da modificação do habitat, translocação de comunidades e inserção de mão de obra de diferentes partes do país. Modificações da paisagem natural resultam em provocações sociais que, por sua vez, podem trazer implicações no sistema econômico regional. 


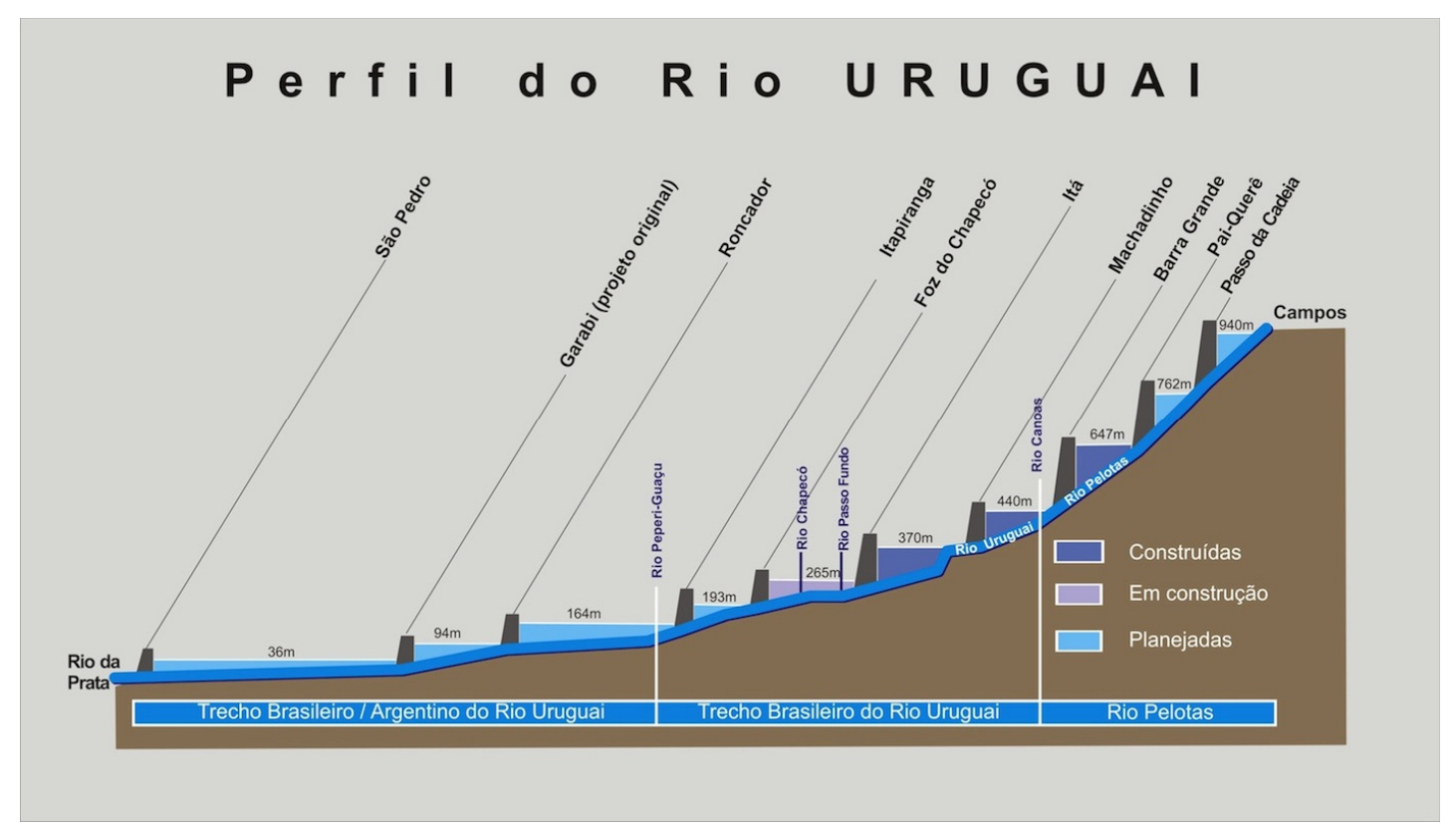

Figura 1: Perfil do Rio Uruguai mostrando as barragens construídas, em construção e planejadas (Adaptado a partir de Paim e Ortiz, 2006). Fonte: Neno Brazil, 2010.

Historicamente a erva mate foi o principal produto de comercialização dos caboclos, baseado na economia de subsistência. Ao longo dos anos o enquadramento dos caboclos foi feito em áreas impróprias para pecuária e agricultura, coincidindo com o surgimento das propriedades rurais familiares. A este fato segue o comércio da madeira, na década de 30, com a utilização de balsas de transporte (WOLOSZYN, 2006). Observa-se que, já nessa época, a economia e a modificação da paisagem estão fortemente relacionadas. Caminham juntas, como que imitando a sucessão ecológica observada em ecossistemas. Do corte das árvores, à formação das pastagens e em seguida o desenvolvimento da agricultura, tudo parece seguir um script natural e lógico. Entretanto, a sofisticação do comércio e das relações humanas ao longo do tempo, como por exemplo a globalização, exigem ações do poder público que podem ser resumidas na definição de políticas públicas baseadas em um planejamento e gestão mais eficiente da paisagem remanescente original e da artificial.

Os números relativos a Bacia do Rio Uruguai são, em sua maioria, superlativos. A área total da Bacia é de $384.000 \mathrm{~km}^{2}$, sendo que, $45 \%$ desta área está localizada em território Brasileiro. São 384 municípios que representam uma população de 3.8 milhões de pessoas. O volume de água que flui pela calha do Rio Uruguai é, em média, $114 \mathrm{~km}^{3}$ por ano (PAIM; ORTIZ, 2006) (Figura 2).

Trata-se de uma importante região agrícola e agropastoril, sendo que, o turismo, como força econômica, pode ainda ser considerado como incipiente. Ou seja, na área de estudo, o turismo ainda contribui muito pouco para a economia do Estado de 
Santa Catarina. Portanto, pode-se afirmar que o potencial de crescimento é substancial mas, o mais importante, é que se apresenta uma oportunidade única para se discutir a implantação de um turismo de conservação, mais brando do ponto de vista ambiental e baseado na pesquisa e no desenvolvimento comunitário. Some-se a isso o fato da área de estudo ser ainda pouco estudada e, como consequência, existirem poucos dados disponíveis. Tal situação afeta particularmente o planejamento e gestão, principalmente no que diz respeito ao turismo.

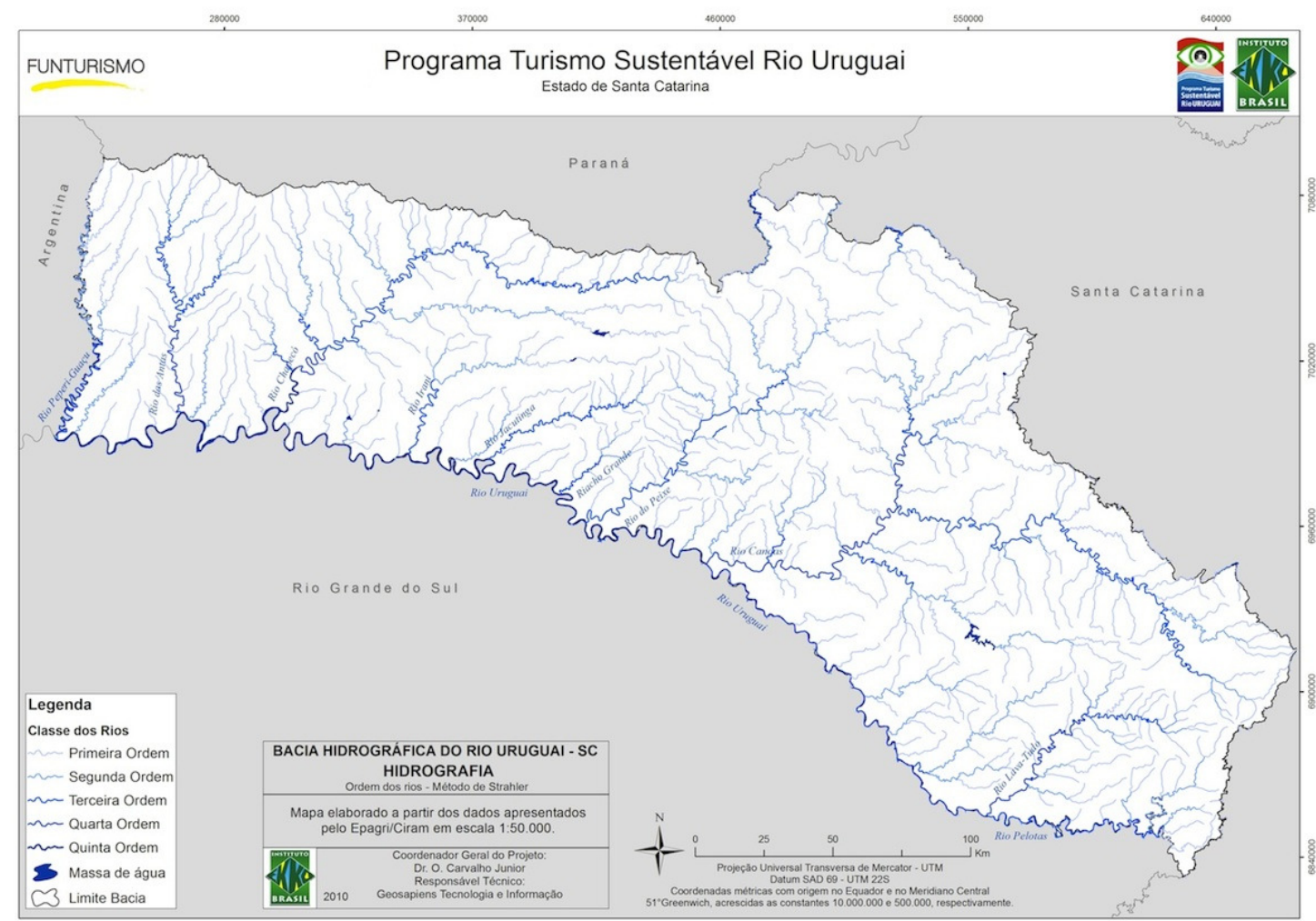

$\mathrm{F}$

Figura 2: Hidrografia da Bacia do Rio Uruguai, lado catarinense. Fonte: Programa Turismo Sustentável Rio Uruguai, Instituto Ekko-Brasil, 2010.

O Sistema de Informação Geográfico (SIG) é a ferramenta utilizada para criação do banco de dados e confecção de mapas temáticos. O Projeto tem como propósito auxiliar em tomadas de decisões voltadas para ações empreendedoras, geração de renda, criação de novas oportunidades de trabalho, além de auxiliar em ações que objetivam o resgate e valorização da cultura local e regional. Trabalho semelhante foi realizado com sucesso para a Bacia Hidrográfica do Rio Itajaí (CARVALHO-JUNIOR, 2009). Na oportunidade, um Atlas Digital Interativo foi criado com o objetivo de disponibilizar os dados gerados (http://www.atlasrioitajai.org/index.html). 
A bacia catarinense do Rio Uruguai e o turismo de conservação como ferramenta ao desenvolvimento sustentável regional

A Bacia do Rio Itajaí, juntamente com a Bacia do Rio Uruguai, representam as maiores bacia hidrográficas do Estado de Santa Catarina. O PIB per capita total para a Bacia do Rio Uruguai, reunindo todos os municípios catarinenses ali presentes, é de $\mathrm{R} \$ 2.006 .640,00$ (IBGE, 2009). O presente trabalho mapeia as principais atividades potenciais e em curso, além de procurar dar subsídios para que as comunidades localizadas ao longo do rio, na área de estudo, possam gerenciá-las da forma mais sustentável e responsável possível. Para tanto, dados espalhados em várias plataformas são organizados e disponibilizados de forma democrática e transparente.

\section{Métodos}

Após levantamento bibliográfico sobre o Rio Uruguai para determinação do status de conhecimento da área de estudo, imagens de satélite foram utilizadas para reconhecimento preliminar. De posse dessas informações foi estruturado um banco de dados em SIG da Bacia do Rio Uruguai. O primeiro passo consistiu na elaboração da arquitetura do banco de dados compatível ao software específico de Sistema de Informações Geográficas (SIG). Para tanto foi feito uma análise, seleção e estruturação dos dados levantados na fase de implementação do projeto. Esta fase inclui entrada, manipulação e análise dos dados.

O trabalho realizado é feito com base em imagens orbitais do satélite LANDSAT ETM7+, nas bandas do infravermelho 4 e 7, e bandas do visível 3, 2 e 1. Composições coloridas também são realizadas com o objetivo de se extrair informações sobre a área de estudo. De maneira geral, o banco de dados é alimentado com dados obtidos de diferentes agências governamentais, associações comerciais, Organizações-Não-Governamentais e instituições de ensino e pesquisa. Os dados são organizados em temas como Associações de Municípios, Colonização, Cultura, Densidade Populacional, IDH, PIB, Turismo de Aventura, Festas, Lazer, Hospedagem, Instituições de Ensino, Enem, Enem- Média, Produção Agrícola (Erva-Mate, Maçã, Pinhão, Pinho, Uva), Ferrovias, Veículos, Hospitais, Limites das Secretarias de Desenvolvimento Regional, Número de Habitantes, Pesque\&Pague, Unidades de Conservação-Estadual, Unidades de ConservaçãoFederal, Unidades de Conservação-Municipal e Unidades de Conservação-RPPN.

Uma expedição científica para coleta de dados de campo também foi planejada e um vídeo sobre a mesma foi produzido. Posteriormente esse vídeo recebeu um prêmio no Festival Internacional TourFilm Brazil, na categoria Natureza e Ecologia (http://www.tourfilmbrazil.com/videos/ne-010/). Para a amostragem de campo, a área de estudo foi dividida em três seções: Celso Ramos a Itá, Itá a Palmitos e Palmitos a Itapiranga (Figura 3). Estas áreas foram percorridas utilizando veículos automotores e embarcações a remo e a motor. O ponto inicial é definido na confluência do Rio Canoas e Rio Pelotas, aos $27^{\circ} 36^{\prime} 30^{\prime \prime}$ e e $51^{\circ} 27^{\prime} 32$ "O. 

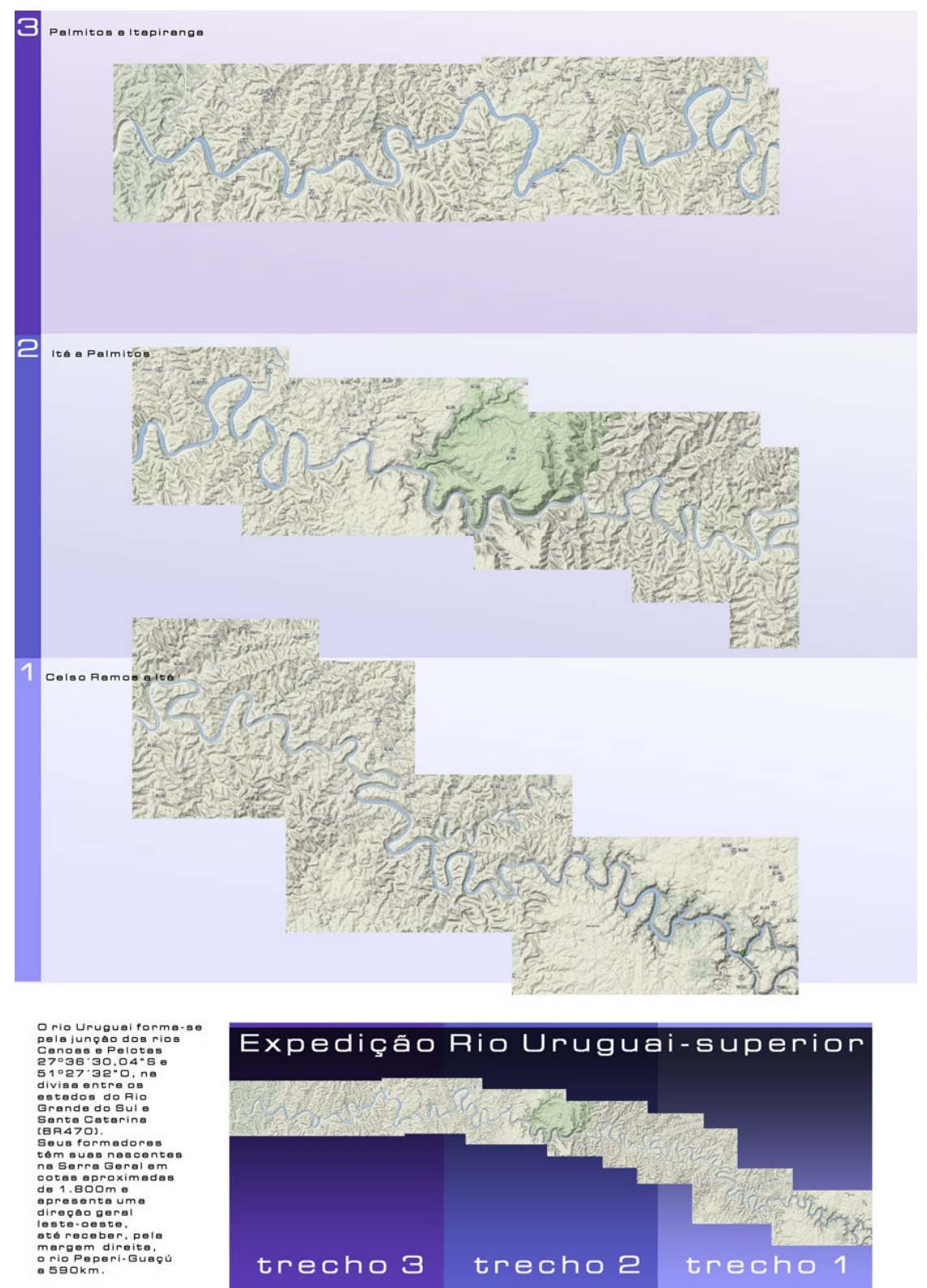

Figura 3: A área de estudo é organizada em 3 seções, percorridas fazendo uso de carros e embarcações. Fonte: Neno Brazil, 2010.

\section{Resultados}

Os resultados são agrupados em dois grupos: Bacia Hidrográfica e Secretaria de Desenvolvimento Regional (SDR). Os mapas temáticos abordam fenômenos geográficos e ambientais, além de dados demográficos, econômicos, agrícolas, culturais e turísticos. São 30 mapas temáticos produzidos a nível de Bacia Hidrográfica e 10 conjuntos de mapas temáticos para cada uma das 18 Secretarias Regionais. A Bacia 
A bacia catarinense do Rio Uruguai e o turismo de conservação como ferramenta ao desenvolvimento sustentável regional

inclui 149 municípios, contemplados dentro das respectivas SDRs. Ao final, são produzidos um total de 210 mapas temáticos para toda a Bacia Hidrográfica do Rio Uruguai/Santa Catarina.

O município de Chapecó se destaca quanto a densidade populacional com 279 habitantes $/ \mathrm{km}^{2}$, seguido por São Miguel do Oeste com 151, Maravilha com 137, Pinhalzinho e Videira com 123, Xanxerê com 112, e Joaçaba com 119 hab $/ \mathrm{km}^{2}$ (Figura 4). Quando se observa a distribuição da população, os dois municípios que chamam atenção são Chapecó com 174.187 habitantes e Lages com 167.805 habitantes.

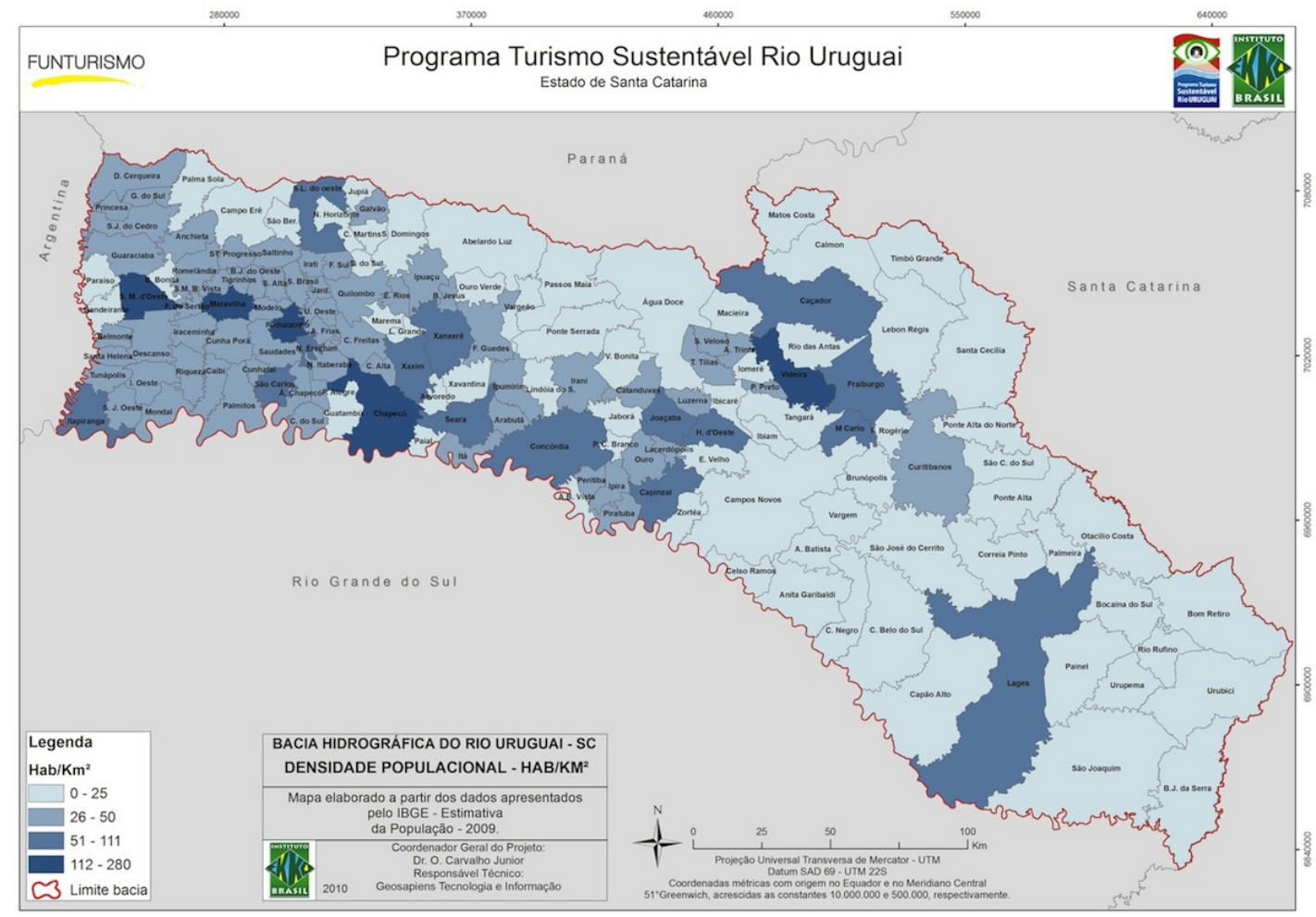

Figura 4: Distribuição da densidade populacional na Bacia Hidrográfica do Rio Uruguai/Santa Catarina. Fonte: Programa Turismo Sustentável Rio Uruguai, Instituto Ekko-Brasil, 2010.

Interessante notar que o PIB per capita não se encontra nos municípios com maior número de habitantes. Treze Tílias com $\mathrm{R} \$ 51.276,00$, Vargem Bonita com $\mathrm{R} \$ 39.481,00$ e Cordilheira Alta com $\mathrm{R} \$ 35.033,00$ representam os municípios mais ricos, com populações de $6.004,4.279$ e 3.531 habitantes, respectivamente. Considerando que o PIB médio dos municípios da Bacia é de $R \$ 13.467,38$, estes três municípios se destacam fortemente.

As principais atividades econômicas desses municípios estão baseadas na pecuária e turismo (Treze Tílias), na agricultura e indústria de madeira e papel (Vargem 
Bonita) e na agricultura e pecuária (Cordilheira Alta). O turismo, como atividade econômica relevante é registrado apenas para Abelardo Luz e São Domingos na SDR de Xanxerê, Irani e Peritiba na SDR de Concórdia, Águas de Chapecó, São Carlos e Palmitos na SDR de Palmitos, Treze Tílias na SDR de Joaçaba, Curitibanos na SDR de Curitibanos, Lages e Painel na SDR de Lages, Bom Jardim da Serra e São Joaquim na SDR de São Joaquim (www.sc.gov.br). Isso corresponde a apenas $8,7 \%$ do total de municípios presentes na Bacia.

De um total de 149 municípios, apenas 15 apresentaram atividades de turismo de aventura, representando apenas $10 \%$ do total. Das atividades listadas, as praticadas na área de estudo são canoagem, tirolesa, escalada, arvorismo, rapel, pesca, rafting, rally, ciclismo, trilhas, vôo livre, e canoismo (Santur - Santa Catarina Turismo S/ A. Acesso em 26/05/10). A distribuição das modalidades de turismo de aventura na área de estudo podem ser organizadas por SDR e são apresentadas na Figura 6.

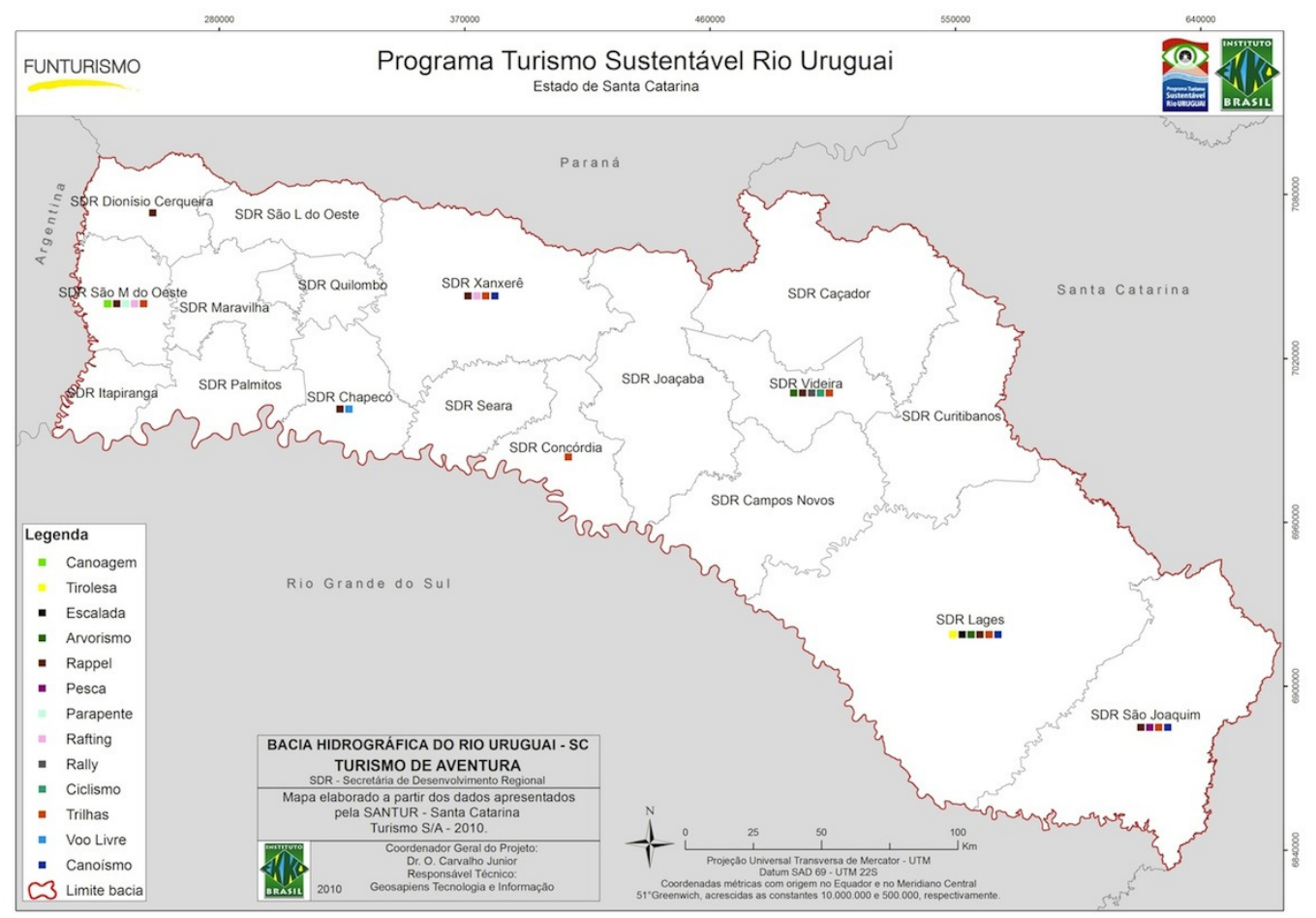

Figura 5: Distribuição das modalidades de turismo de aventura por SDR. Fonte: Programa Turismo Sustentável Rio Uruguai, Instituto Ekko-Brasil, 2010.

Das atividades listadas, o rapel, seguido de trilhas e canoismo, representam as modalidades mais praticadas na área de estudo. Logo atrás vem o rafting e o arvorismo. A pesca, apesar do Rio Uruguai representar um importante ecossistema para espécies como o dourado, é inexpressiva. 
A bacia catarinense do Rio Uruguai e o turismo de conservação como ferramenta ao desenvolvimento sustentável regional

O turismo de aventura e o ecoturismo talvez sejam as atividades turísticas que mais se aproximam do turismo de conservação (LINBERGH; HAWKINS, 2002; SOUZA et al., 2010). Dentre outros produtos que apresentam potencial atrativo para o turismo de conservação pode-se destacar a uva, maçã, pinhão, erva-mate e nó de pinho. A produção de uva dentro da Bacia Hidrográfica ocorre principalmente nos municípios de Tangará, Pinheiro Preto e Videira na SDR de Videira e Caçador na SDR de Caçador, todos com valores acima de 1.651 toneladas/ano.

Com relação a cultura da maçã os principais municípios produtores são: São Joaquim e Fraiburgo, seguidos por Bom Jardim da Serra, Bom Retiro, Monte Carlo e Lebon Regis. O pinhão tem um potencial significativo para o turismo pelo fato de ser coletado da Araucária, uma espécie que representa um bioma ameaçado e de distribuição limitada no território brasileiro. Santa Catarina ainda possui reservas significativas desse ecossistema, sendo que o maior produtor de pinhão é o município de Água Doce na SDR de Joaçaba, seguido por São Joaquim, Lages e Painel.

A erva mate representa outro produto singular na área de estudo e que chama a atenção para o turismo. Todo o ritual do preparo da erva, até a preparação e apreciação do mate, merece destaque dentro da cultura e tradição regional. Várias ervateiras podem ser encontradas na área de estudo, produzindo ervas de sabores e paladares diferenciados. O principal produtor de erva mate é Abelardo Luz, seguido por Chapecó, Xaxim, Ponte Serrada, Vargem Bonita, Jaborá, Água Doce, Caçador, Lebon Régis e Timbó Grande.

Outro sub-produto oriundo da Araucária é o nó-de-pinho, muito utilizado em lareiras e fogões à lenha. $O$ nó-de-pinho atinge valor expressivo no mercado e pode representar uma fonte alternativa de renda para as comunidades, desde que explorado de forma sustentável. Atualmente o principal produtor de pinho na área de estudo é Curitibanos, com uma produção de cerca de 60 toneladas ao ano.

As médias do Exame Nacional do Ensino Médio (ENEM) se equivalem, girando em torno de 48,29 para os municípios da Bacia. Com relação ao ensino superior foram mapeadas 24 instituições com destaques à Chapecó, Caçador e Lages com 3, 4 e 3 universidades, respectivamente. A Figura 6 mostra as médias superiores e inferiores a média do ENEM, considerando o valor fixado pelo MEC em 50 . Do total de municípios presentes na área de estudo, 31\% apresentam média inferior à média nacional e $69 \%$ superior a média nacional.

O número de instituições de ensino variam na área de estudo. Como era de se esperar, o maior número de instituições de ensino está localizado nos municípios com as maiores populações, como Lages e Chapecó, apresentando números que variam de 120 a 227 instituições. Outros municípios que se destacam com valores variando de 37 a 119 instituições são São Joaquim, São José do Cerrito, Curitibanos, Campos Novos, Fraiburgo, Videira, Joaçaba, Caçador, Concórdia, Xanxerê e São Miguel do Oeste. 


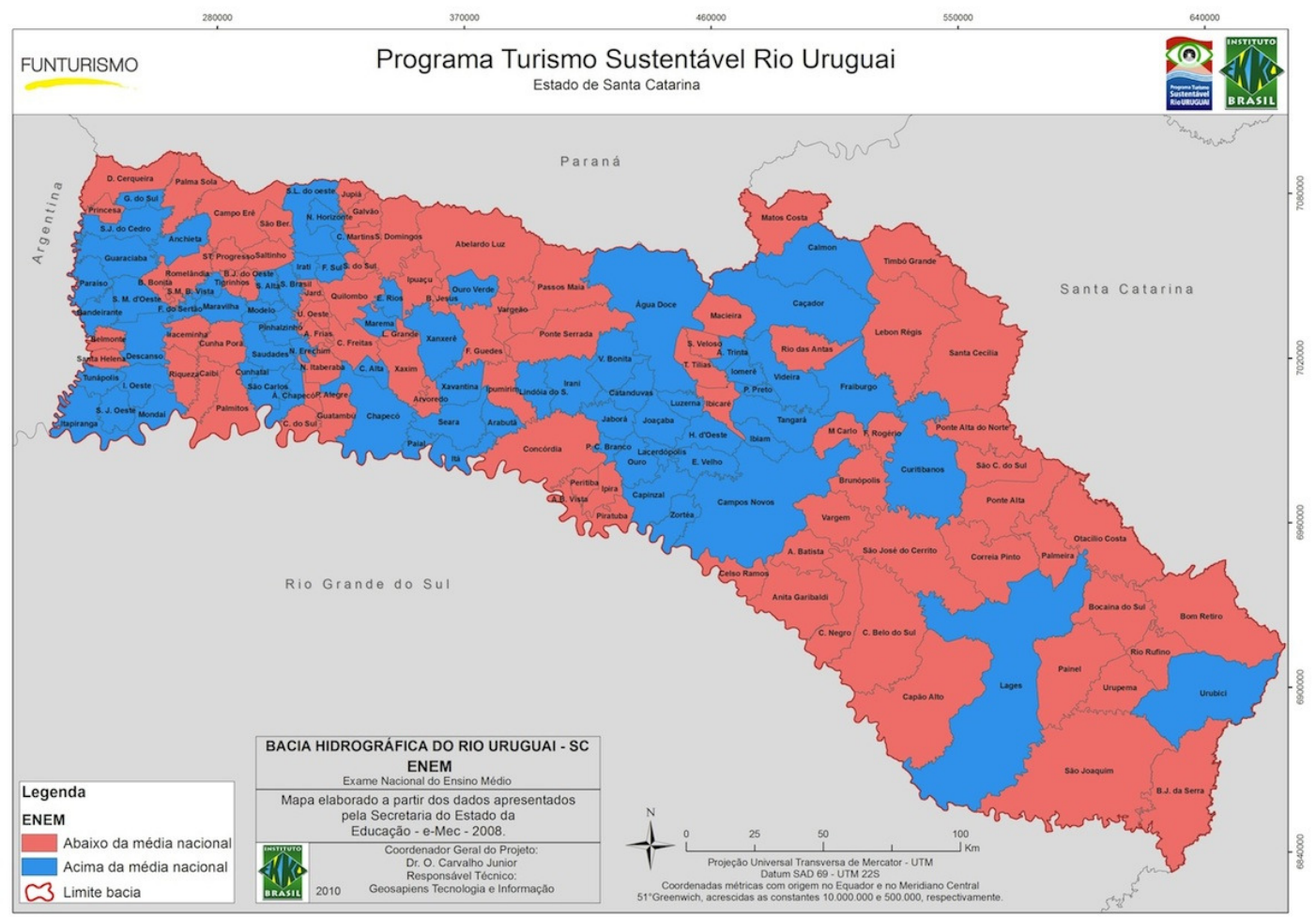

Figura 6: Distribuição dos municípios que apresentam médias superiores e inferiores a média do ENEM. Fonte: Programa Turismo Sustentável Rio Uruguai, Instituto Ekko-Brasil, 2010.

Associado à pesca pode-se citar o Pesque\&Pague, que é listado como atividade econômica. Municípios como Caçador, Concórdia, Maravilha e Descanso exibem de 3 a 4 Pesque\&Pagues. A aquicultura representa uma atividade expressiva e em crescimento na área de estudo. Se destacam como principais produtores de peixes de água doce a SDR de Caçador, a SDR de Chapecó, e a SDR de São Miguel do Oeste.

Hospedagens do tipo familiar, onde o turista tem contato mais próximo com a comunidade e cultura local são as que mais chamam a atenção. Infelizmente esse tipo de informação não está disponível e exige um trabalho de campo específico, com objetivo de cadastrar as pousadas familiares existentes.

Da mesma forma que a hospedagem, a infra-estrutura relacionada ao transporte pode ser decisiva para o desenvolvimento do turismo. A maior concentração de linhas ferroviárias está na região entre Campos Novos e Caçador. Pode-se afirmar que esse tipo de transporte tem ainda pouca influência para o turismo, principalmente pelo fato de cortar a região de estudo no sentido norte-sul e não leste-oeste.

A distribuição do Índice de Desenvolvimento Humano (IDH) entre os municípios não varia de forma significativa. O IDH leva em consideração parâmetros como riqueza, alfabetização, educação, esperança de vida e natalidade. A média do IDH para a 
Bacia do Rio Uruguai é de 0,78 , um pouco abaixo da média da Bacia do Rio Itajaí, de 0.80 (CARVALHO-JUNIOR, 2009), e um pouco acima da média nacional. O IDH mínimo de 0.67 é registrado para Irati, na SDR de Quilombo, sendo que o IDH máximo, de 0.87 pertence a Joaçaba, na SDR de mesmo nome.

Os municípios que apresentam os piores valores de IDH, abaixo de 0,7 , além de Irati, são Formosa do Sul, Santiago do Sul, Jardinópolis, Entre Rios, Timbó Grande, Campo Belo do Sul e Cerro Negro. Entretanto, é preciso salientar que nenhum município apresenta IDH abaixo da média nacional, de 0.5.

As Unidades de Conservação (UC) mapeadas na Bacia do Uruguai são RPPNs, UC Municipais, Estaduais e Federais, de diferentes categorias como Parques, Refúgios, Reservas e Florestas. A soma das áreas dessas UC totaliza cerca de 58.473 ha, porém, para algumas unidades, a área é ainda desconhecida e esse número não é exato. A categoria de UC em maior número é a Municipal (Figura 7). Em segundo lugar vem as Unidades Federais com $60 \%$, seguido das Unidades Estaduais com $30 \%$ e as RPPNs com $20 \%$.

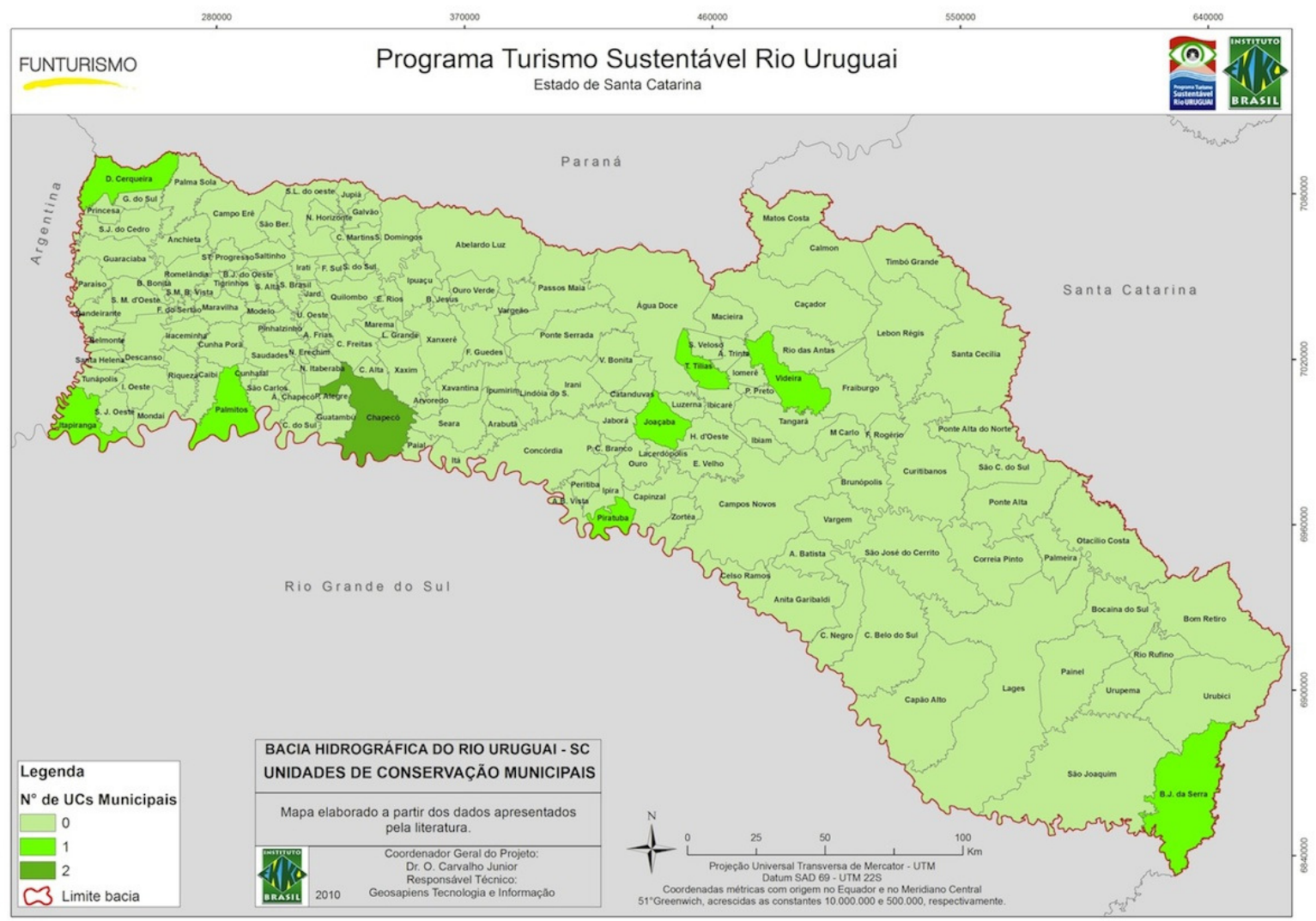

Figura 7: Distribuição das Unidades de Conservação Municipais. Fonte: Programa Turismo Sustentável Rio Uruguai, Instituto Ekko-Brasil, 2010. 
Ao todo, 17 municípios são cortados pelo Rio Uruguai: Campos Novos, Zortéa, Capinzal, Piratuba, Alto Bela Vista, Concórdia, Itá, Paial, Chapecó, Guatambú, Caxambu do Sul, Águas de Chapecó, São Carlos, Palmitos, Caibi, Mondai e Itapiranga.

Uma área de $5 \mathrm{~km}$ às margens e ao longo do Rio Uruguai foi classificada. $\mathrm{O}$ resultado da classificação pode ser observado na Figura 8. A classificação segue os temas definidos pelo IBGE, ou seja: agricultura, corpos d'água, pastagens, silvicultura, vegetação nativa e áreas urbanas.

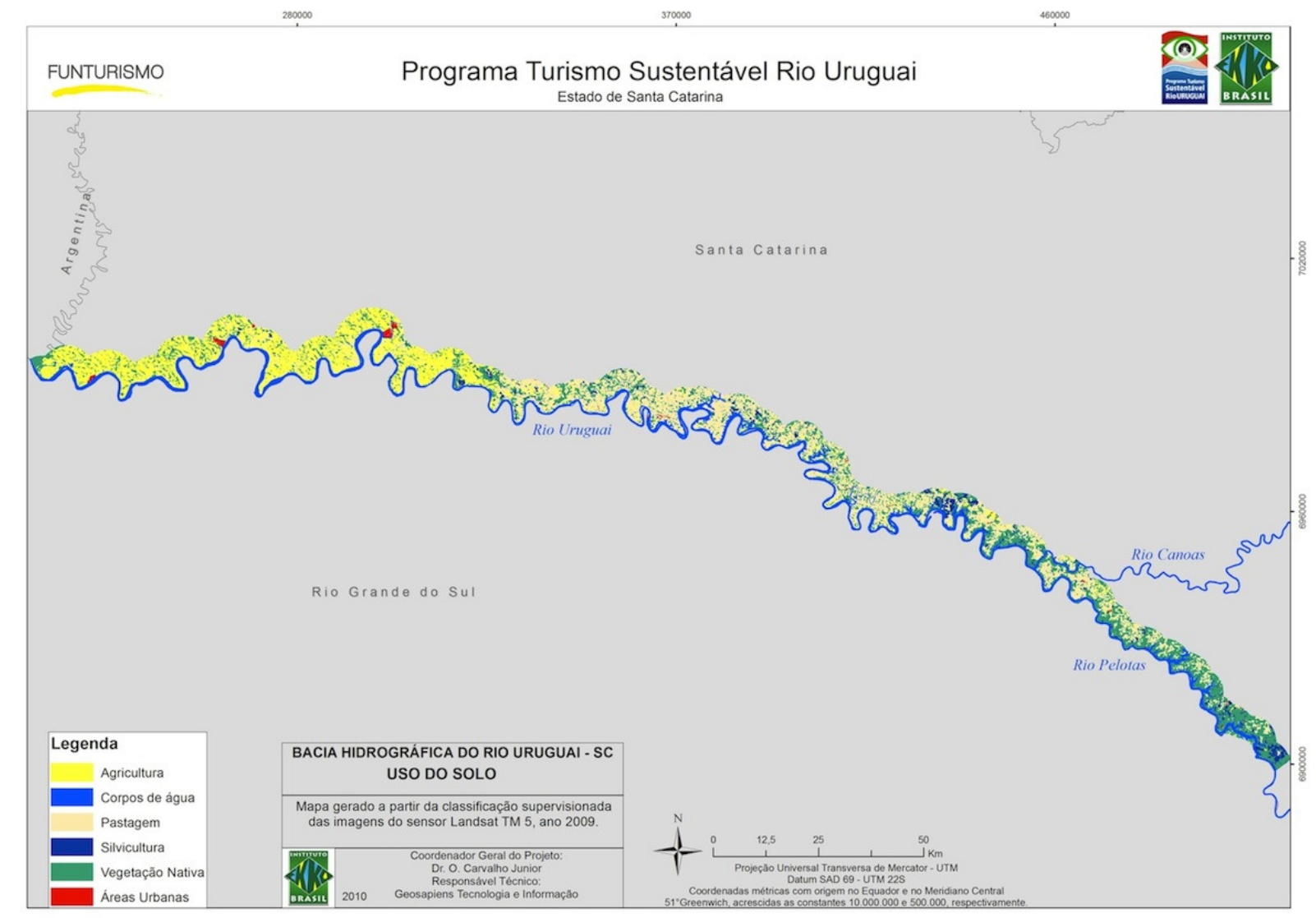

Figura 8: Classificação do uso do solo ao longo do Rio Uruguai, margem catarinense. Fonte: Programa Turismo Sustentável Rio Uruguai, Instituto Ekko-Brasil, 2010.

A Figura 9 apresenta a distribuição em porcentagem das classes definidas nessa faixa de $5 \mathrm{~km}$ ao longo do Rio Uruguai. Como pode ser observado a classe pastagem é a dominante, ocupando $31 \%$ da área total, o equivalente a $765 \mathrm{Km}^{2}$. A pastagem é seguida pela agricultura com $27 \%\left(656 \mathrm{Km}^{2}\right)$, vegetação nativa com $25 \%(629$ $\left.\mathrm{Km}^{2}\right)$, corpos d'água com $11 \%\left(282 \mathrm{Km}^{2}\right)$, silvicultura com $5 \%\left(125 \mathrm{Km}^{2}\right)$ e áreas urbanas com apenas $1 \%\left(16 \mathrm{Km}^{2}\right)$. 


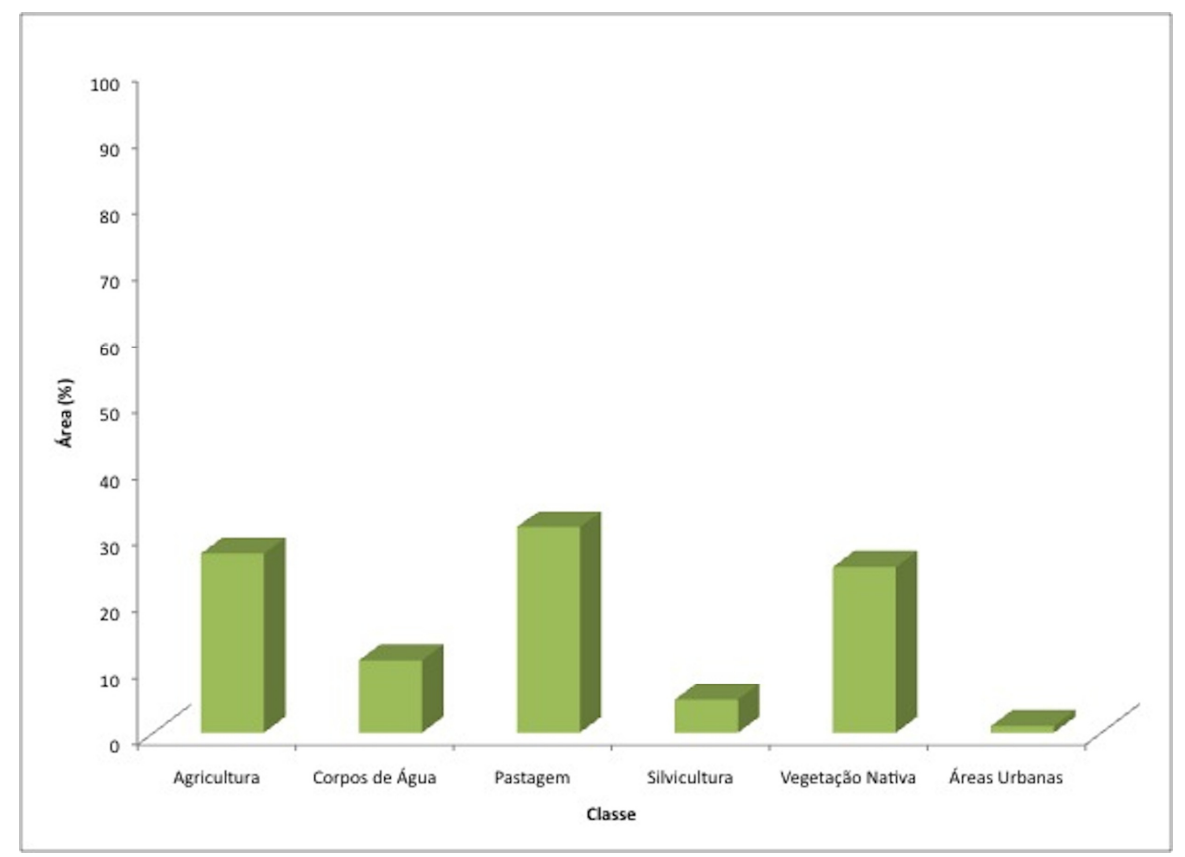

Figura 9: Distribuição das classes de uso do solo ao longo de uma faixa de $5 \mathrm{~km}$ de largura da margem do Rio Uruguai. Programa Turismo Sustentável Rio Uruguai, Instituto Ekko-Brasil, 2010.

Considerando apenas os municípios de Chapecó, Concórdia, Palmitos e Itapiranga, pode-se observar que mais de $20 \%$ da área total de cada um é ocupada por lavoura, sendo que a área ocupada por mata é sempre inferior (Figura 10).

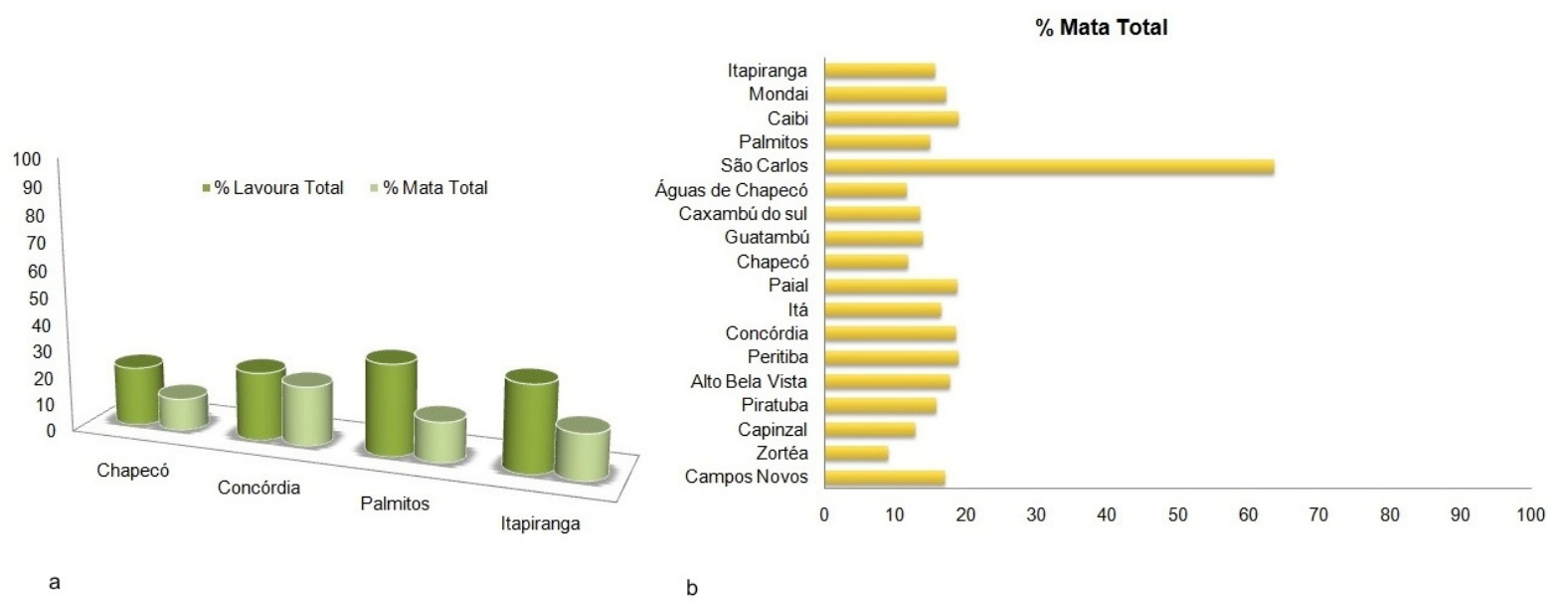

Figura 10: (a) Relação entre áreas ocupadas por lavoura e mata em quatro municípios que margeiam o Rio Uruguai. (b) Porcentagem da área de mata presente nos municípios que margeiam o Rio Uruguai. Programa Turismo Sustentável Rio Uruguai, Instituto Ekko-Brasil, 2010. 


\section{Discussão}

As diferentes modalidades de turismo observadas na área de estudo movimentam um número expressivo de pessoas, porém à nível regional, de forma pontual e restrita. Os recursos produzidos e utilizados são difíceis de serem mensurados pelo fato de se distribuírem por vários setores da economia (DIAS, 2007). Modalidades de Turismo como o de Conservação de Base Comunitária tem como um dos objetivos o envolvimento da comunidade.

Uma pousada, por exemplo, deve, preferencialmente, ser operada e administrada pela própria família. Para tanto, esta deve ser devidamente preparada. A educação, nesse particular, é de fundamental importância. As intervenções necessárias, como por exemplo, cursos de capacitação, desenvolvimento de lideranças locais, e valorização da cultura local, são facilitadas se planejadas e geridas a partir de bancos de dados estruturados e disponíveis.

Quando se fala em Turismo de Conservação de Base Comunitária é imprescindível que o público alvo seja bem definido. Esse tipo de turismo obviamente necessita de um público consumidor. O público alvo faz parte de um nicho de mercado turístico ainda pouco explorado. Tratam-se de pessoas que viajam sozinhas, ou em pares, ou em família (CARVALHOJUNIOR; SCHMIDT, 2004).

Os resultados revelam áreas com baixos níveis de intervenção urbana ao longo das margens do Rio Uruguai. Estas áreas ribeirinhas representam excelentes oportunidades para conservação e desenvolvimento de zonas recreacionais. Por outro lado, isso não significa que as áreas impactadas não possam ser recuperadas e aproveitadas economicamente para o turismo responsável.

De maneira geral, a porcentagem de área de mata não ultrapassa os $20 \%$ da área total de cada município, com exceção de São Carlos que surpreendentemente apresenta quase $70 \%$ de área coberta por florestas (Figura 10a e 10b). São Carlos se destaca também pela presença de águas minerais alcalinas, sulfatadas e bicarbonatadas, que impulsionam o turismo local. Campings, Parques Aquáticos, Hotéis e Pousadas fazem parte da estrutura voltada ao turismo. O fato do turismo ser economicamente importante para o município, pode estar auxiliando na preservação dos ambientes naturais.

Analisando a área de APP como um todo, ao longo do Rio Uruguai, fica claro que o fato de área florestada ainda chegar próximo aos $20 \%$ do total é altamente positivo. A presença de florestas traz um pouco de esperança e otimismo para o planejamento e implantação de uma política de turismo de conservação.

O desenvolvimento urbano ao longo das margens do Rio Uruguai não pode ser comparado em intensidade ao observado ao longo do Rio Itajaí, mas, independente disso, onde se faz presente, acaba por prejudicar as estruturas construídas por processos naturais tais como erosão e flutuações do nível da água. Da mesma forma, estruturas rígidas, construídas dentro do corpo d'água, por exemplo, barragens, interrompem processos naturais ecológicos e resultam na deterioração dos ecossistemas.

Remanescentes florestais em áreas marginais a corpos d'água são concentradores da biota local e importantes para a conservação de espécies silvestres. Além disso, áreas marginais a corpos d'água são definidas por lei como Áreas de Preservação Permanente (APP) pelo Código Florestal, Lei 4.771/65. O Art. 1, §2 (II) estabelece que a área de APP possa estar ou não, coberta por vegetação nativa. Isto porque a função principal de uma APP, de acordo 
A bacia catarinense do Rio Uruguai e o turismo de conservação como ferramenta ao desenvolvimento sustentável regional

com a Lei, é a de preservar, entre outras, o corpo d'água, a biodiversidade e o fluxo gênico da fauna e da flora.

Fica claro que o desafio do pesquisador é encontrar o melhor caminho, que abra espaço para tomadores de decisão, conciliando a conservação com a qualidade de vida das comunidades envolvidas (SANT'ANA; RICCI, 2008; GOMES; SANTOS, 2007). É nesse sentido que a zona de APP ao longo do Rio Uruguai é analisada no presente trabalho. Para rios que apresentem larguras de 200 (duzentos) a $600 \mathrm{~m}$ (seiscentos metros), a faixa de APP resultante é de 100 metros, portanto, a maior parte do Rio Uruguai em questão.

$\mathrm{Na}$ área de estudo, um segmento de destaque no turismo, voltado para a natureza, é o ecoturismo. O ecoturismo representa uma atividade que vem abrindo novos espaços para outras modalidades de turismo (LINDBERG; HAWKINS, 2002). Entre as modalidades comumente confundidas com o ecoturismo existentes na área de estudo se inclui o turismo de aventura, como o Rafting, o Rappel, Trilhas, Vôo Livre, Hotel Fazenda e Pesque\&Pague. Entretanto, essa lista diminui quando o assunto passa a ser o turismo de conservação.

Para que uma determinada atividade seja classificada como sendo de turismo de conservação, ela deve obedecer a certos critérios como o de (1) apresentar mínimo impacto ao ambiente e a cultura da comunidade anfitriã, (2) possuir um programa ou projeto que inclua pesquisa e/ou educação ambiental, (3) represente um negócio responsável e integrado com a comunidade e o governo, (4) parte do lucro seja revertido para a manutenção das atividades de pesquisa e educação ambiental, e (5) reciclagem e uso de energias alternativas.

Importante ressaltar que segmentos como ecoturismo, turismo sustentável ou responsável e o próprio turismo de conservação, devem manter um alto nível de satisfação entre os turistas e participantes. Isto significa que, principalmente para estes casos, a experiência para os turistas precisa ser significativa. Um exemplo de experiência significativa é aquela que aumenta o nível de consciência ambiental e cultural (BACAL et al., 2007). Esse nível de satisfação proporcionado ao turista exige um preparo significativo da comunidade onde a qualidade de vida representa o norte do planejamento.

Os dados de IDH dão uma amostra do potencial que a Bacia do Rio Uruguai possui para o desenvolvimento de um turismo sustentável, responsável e/ou de conservação. Educação, por exemplo, é um fator primordial para o estabelecimento de práticas sustentáveis. Entretanto, esse movimento em direção ao turismo de conservação deve estar em sintonia com os ideais comunitários (SAMPAIO et al, 2005). A mudança, nesse caso, é baseada na busca de um modelo alternativo que proporcione satisfação, saúde, estilo de vida social diversificado, ao mesmo tempo em que minimiza os impactos ambientais.

O desenvolvimento do turismo de conservação pode representar uma importante opção econômica. Entretanto, a atividade deve ser baseada em técnicas sustentáveis, possuir um viés social e econômico, apoiar projetos de conservação (ou mesmo desenvolver algum), além de envolver a comunidade local.

No trabalho desenvolvido na Bacia Hidrográfica do Rio Itajaí, por exemplo, nenhuma atividade turística pôde ser enquadrada como sendo de conservação. Na busca de informações em guias como o Lonely Planet ou mesmo o Quatro Rodas, percebe-se como o Rio Itajaí e o Rio Uruguai, são poucos contemplados. Nesse particular, estamos falando de um público alvo como aquele que viaja sozinho ou em pequenos grupos, por conta própria, e que busca acomodações alternativas como pousadas familiares. 
Esse tipo de público, na Europa, é comumente enquadrado na modalidade Turismo Responsável (http://www.responsibletravel.com/ e http://www.atlasrioitajai.org/index.html). O Projeto Lontra, por exemplo, com base na Ilha de Santa Catarina, é um dos projetos brasileiros anunciados pelas Agências Responsible Travel (http://www.responsibletravel.com/Trip/ Trip901739.htm), com base na Inglaterra, e Ecovolunteer Program (www.ecovolunteer.org), com base na Holanda.

A participação ativa e direta de turistas dentro do turismo de conservação é fundamental. Esta não pode ser vista apenas dentro de uma perspectiva econômica ou financeira. Nesse particular o ecoturismo é o que talvez mais se aproxima do turismo de conservação.

Atenção especial deve ser dada aos impactos potenciais das atividades do turismo de conservação no ambiente e na comunidade. A sustentabilidade dessa modalidade é fortemente relacionada com a manutenção da biodiversidade na área de conservação (CARVALHO-JUNIOR; SCHMIDT, 2004). Comunidade, ecoturismo e proteção ambiental, quando juntas, podem promover o desenvolvimento social e econômico com a conservação da biodiversidade.

A participação da comunidade é chave no processo. Qualquer proposta deve ser compreendida pela comunidade local. Entretanto, para que isso aconteça a educação é importante e isso implica em ações a médio e longo prazo. A necessidade da inclusão de atividades sociais dentro de proposta de gestão ambiental pode ser decisiva no sucesso do planejamento e gestão dos recursos naturais como resultado da educação e participação comunitária.

O presente trabalho considera a Bacia Hidrográfica como uma unidade de gestão. Dentro dessa unidade de gestão, as florestas, os rios e a fauna, por exemplo, são considerados recursos naturais turísticos. A implementação de uma política de turismo sustentável, tendo uma Bacia como unidade de gestão, faz por exigir que os recursos naturais ali presentes sejam gerenciados de maneira integrada, considerando, por exemplo, a economia, cultura, esporte e ambiente.

A ONU define Desenvolvimento Sustentável como aquele que deve garantir as necessidades das atuais gerações sem comprometer as gerações futuras. Já o Turismo Sustentável, segundo o PNMT (Programa Nacional de Municipalização do Turismo), lançado pela EMBRATUR em 1994, é o turismo explorado de forma consciente, organizada e planejada, de forma a garantir a continuidade do mesmo. O PNMT representa um modelo de desenvolvimento econômico criado para assegurar a qualidade de vida da comunidade. Ao mesmo tempo, esse modelo deve proporcionar satisfação ao turista e manter a qualidade do ambiente.

O presente trabalho busca relacionar as principais atividades econômicas com a expectativa do desenvolvimento do turismo de conservação na área de estudo. A análise é feita a partir da realidade econômica atual onde a produção agrícola representa um dos principais motores da economia na bacia. Dentro desse contexto a produção de erva-mate, uva e pinhão, por exemplo, são consideradas como um potencial atrativo turístico. Entretanto, isso deve ser analisado a luz da infra-estrutura presente, como aeroportos, ferrovias e hospedagens. Nesse sentido ainda há muito a se fazer. Ferrovias, por exemplo, são restritas à uma pequena área dentro da Bacia.

A presença de hospitais também pode ser um fator importante para o turismo. A segu- 
A bacia catarinense do Rio Uruguai e o turismo de conservação como ferramenta ao desenvolvimento sustentável regional

rança com relação à saúde do turista pode ser um ponto fundamental para a escolha do destino por vários grupos, em especial o publico que se expõem à riscos, como é o caso do ecoturismo, turismo de aventura e turismo de conservação, ou público da terceira-idade. Dois municípios se destacam com a presença de 3 hospitais, Lages e São Miguel d'Oeste. De maneira geral a área de estudo é bem servida por hospitais. Municípios que não possuem hospital podem contar com um no município vizinho.

O planejamento e gestão do turismo responsável para a área de estudo deve necessariamente levar em consideração as outras atividades econômicas, de forma a se integrarem e se complementarem o máximo possível. Atividades de uso conflitivo com o turismo devem ser determinadas de forma a ser possível a tomada de decisões que tragam benefícios para todos os envolvidos. Exemplo disso são as barragens que se multiplicam ao longo do Rio Uruguai. A produção de energia não deve ser menosprezada, mas a atividade precisa ser compatível com outras formas econômicas alternativas em curso, futuras e mesmo ainda desconhecidas.

Um aspecto importante a ser considerado nesse projeto é o status de conservação dos ecossistemas. Dentro da Bacia Hidrográfica do Rio Uruguai existem apenas 21 Unidades de Conservação de diferentes categorias, 2 RPPNs, 10 Unidades de Conservação Municipais, 3 Unidades de Conservação Estaduais e 6 Unidades de Conservação Federais. A soma das áreas dessas UCs totaliza cerca de $585 \mathrm{~km}^{2}$, o que representa algo em torno de $1.17 \%$ da área da Bacia $\left(50.200 \mathrm{~km}^{2}\right)$.

Unidades de Conservação são parte importante da política ambiental brasileira, como forma de conservar a biodiversidade e promover o desenvolvimento sócio ambiental (ICMBio, 2010). Parcerias estratégicas entre Instituições Públicas, Organizações Não Governamentais e Empresas Privadas são fundamentais na implementação de políticas voltadas, por exemplo, à implementação do turismo de conservação.

Projetos de pesquisa associados à participação de ecovoluntarios brasileiros e estrangeiros podem estimular a abertura de empreendimentos novos como pousadas familiares e/ ou ecológicas, além de ajudar no desenvolvimento do comércio local. Este tipo de atividade acaba por resgatar o orgulho da população local com a própria cultura e tradição, já que estas são atrativos importantes nesse tipo de turismo.

O turista moderno está preocupado com a conservação do ambiente e com a biodiversidade. Este turista está à procura de trilhas e ambientes que proporcionam momentos de lazer associados com áreas selvagens e experiências únicas. Projetos de conservação desenvolvidos na área devem proporcionar informação e conhecimento ao turista, além de apresentar um viés social e econômico para as comunidades ali presentes. Nesse particular, a criação de APAs (Área de Proteção Ambiental) pode ser uma opção à figura de Parque, pois possibilita o desenvolvimento de projetos e atividades sustentáveis, sem prejuízo social e econômico, e com melhoria da qualidade de vida.

Uma política de gestão integrada do turismo da Bacia, deve ser resultado de um processo de aprendizagem coletivo onde as várias partes devem ser incluídas. O empreendedor, por exemplo, deve ser um ator atuante. A gestão integrada representa uma ferramenta útil que pode trazer benefícios financeiros, emprego, melhor qualidade de vida e mais eficiência para o governo. Pode-se esperar situações de conflitos entre partes durante um processo de gestão integrada. Entretanto, estas situações podem ser revertidas em oportunidades, se tratadas de forma integrada e bem administradas. 
A utilização do SIG, como instrumento de gestão se mostrou bastante útil devido à possibilidade de gerenciamento de grande volume de dados, análise do mundo real e simulações de situações diversas. Soma-se a isso o fato de que novos dados podem ser incorporados ao sistema a qualquer momento, tornando mais segura qualquer tomada de decisão ou solução de uso conflitivo.

A conservação ambiental e o desenvolvimento com qualidade de vida das comunidades envolvidas devem ocupar lugar de destaque no planejamento do turismo na Bacia. As alterações da paisagem na área de estudo, resultaram na fragmentação de habitats ao longo do tempo, que hoje se apresentam como um mosaico de manchas verdes com diferentes graus de isolamento. Efeitos da fragmentação de habitats sobre as populações animais e florestais são ainda pouco conhecidas. Entretanto, um consenso entre os pesquisadores é de que áreas isoladas são pouco eficientes na manutenção da população de certos táxons (CARVALHO-JUNIOR et al., 2006).

A continuidade do presente programa deve incluir a seleção de áreas estratégicas dentro da Bacia, tendo como base critérios técnicos, políticos e logísticos. O presente trabaIho pode servir como um importante indicador de áreas prioritárias para uma análise mais detalhada. De nada vale planejar e gerenciar projetos sem que estes não incluam benefícios sociais e culturais para as comunidades envolvidas. As comunidades devem representar a parte mais beneficiada de todo o processo.

\section{Referências Bibliográficas}

BACAL, S. S.; MELO, A. J. S.; WIDMER, G. M.; PEREIRA, R. S. Turismo sustentável no Brasil: utopia ou possibilidade. Revista Gerenciais, v. 6, n. 4, p. 175-181, 2007.

CARVALHO-JUNIOR, O.; SCHMIDT, A. D. Ecotourism as a Tool for the Conservation of Endangered Species in the Coastal Region of Santa Catarina, Brazil. Journal of Coastal Research, n. 39, p. 959-961, 2004.

CARVALHO-JUNIOR, O.; BIROLO, A. B; LABRUDE, A. S. O conceito de conectividade aplicado a conservação de população de Lontra longicaudis. $V$ Congresso Integrado de Iniciação Científica - UNIDAVI, UNERJ e Unifebe (anais). Jaraguá do Sul (UNERJ) - 29 de setembro de 2006.

CARVALHO-JUNIOR, O. Sistema de Informação Geográfico (SIG) como ferramenta auxiliar para o planejamento e gestão do turismo na Bacia Hidrográfica do Rio Itajaí (Santa Catarina). Caderno Virtual de Turismo, v. 9, n. 1, p. 63-87, 2009.

DIAS, R. Turismo Sustentável e Meio Ambiente. 1. ed. São Paulo: Atlas, 2007.

GOMES, B. M. A.; SANTOS, A. C. Influências das políticas públicas de Turismo nas transações entre os agentes: uma análise sob a ótica da ECT. Revista Brasileira de Pesquisa em Turismo, v. 1, n. 2, p. 72-100, 2007.

HOEFFEL, J. L.; FADINI, A. A. B.; MACHADO, M. K.; REIS, J. C. Trajetórias do Jaguary - Unidades de Conservação, Percepção Ambiental e Turismo: Um Estudo na PA do Sistema Cantareira, São Paulo. Ambiente e Sociedade, v. XI, n. 1, p. 131-148, 2008.

ICMBio. Coleção Biodiversidade Brasileira. ed. São Paulo: Terra da Gente, 2010. 
A bacia catarinense do Rio Uruguai e o turismo de conservação como ferramenta ao desenvolvimento sustentável regional

LEFF, E. Epistemologia Ambiental. ed. São Paulo: Cortez, 2002.

LINDBERG, K. E; HAWKINS, D. E. Ecoturismo: um guia para planejamento e gestão. ed. São Paulo: Senac, 2002.

PAIM, E. S.; ORTIZ, L. S. Hidrelétricas na bacia do rio Uruguai: guia para ONGs e movimentos sociais. ed. Porto Alegre: Núcleo Amigos da Terra/Brasil, 2006.

SAMPAIO, C. A. C.; OYARZÚN, E.; SOUZA, M. S.; CÁRCAMO, C., ANELI-JR, E. Arranjo socioprodutivo de base comunitária: análise comparativa de experiencias de turismo comunitario no Brasil e no Chile. Revista de Negócios. v. 10, n. 4, p. 288-301, 2005.

SANT'ANA, R. e RICCI, F. Turismo sustentável: enfoque no artesanato local na cidade de Santo Antônio do Pinhal, SP. Caderno Virtual de Turismo, v. 8, n. 1, p. 16-26, 2008.

SANTUR. Santa Catarina Turismo S/A. Disponível em http://www.santur.sc.gov.br/ index.php?option=com content\&task=category\&sectionid=4\&id=39\&ltemid=186. Acesso em 26/05/10.

SOUZA, C. S.; BRAGHINI, C. R.; ARAÚJO, L. F. Espaços de diálogo na comunidade para o Ecoturismo: a llha Mem de Sá, Itaporanga D'ajuda (SE). Revista Brasileira de Ecoturismo, v. 3, n. 2, p. 235-248, 2010.

WOLOSZYN, N. Os balseiros do rio Uruguai. In: ZOTTI, S. (Org.). História faz história: Contribuições ao estudo da história regional. Concórdia: Sul Oeste, 2006. v. 1, p. 53-73.

\section{Agradecimentos}

A Petrobras, através do Programa Petrobras Ambiental, tornou possível a expedição para coleta de dados no Rio Uruguai. Ao Neno Brazil pelas figuras 1 e 3. A Pousada Recanto da Ilha Redonda e a Prefeitura de Palmitos que deram todo o apoio e infraestrutura para o desenvolvimento dos trabalhos de campo. Ao Funturismo e a Secretaria de Estado de Turismo, Cultura e Esporte do Estado de Santa Catarina, que tornaram o desenvolvimento de todo o trabalho possível.

Oldemar de Oliveira Carvalho Junior: Instituto Ekko Brasil para Conservação da Biodiversidade, Florianópolis, SC, Brasil.

Email: ocjunior@ekkobrasil.org.br

Link para o currículo Lattes: http://lattes.cnpq.br/6092576258994833

Rafael Sperb: Universidade do Vale do Itajaí, Itajaí, SC, Brasil.

Email: rmsperb@gmail.com

Link para o currículo Lattes: http://lattes.cnpq.br/1619120304203132

Data de submissão: 23 de agosto de 2011

Data de recebimento de correções: 12 de janeiro de 2012

Data do aceite: 15 de janeiro de 2012

Avaliado anonimamente 